\title{
Excessive Interleukin 18 Relate the Aggravation of Indomethacin- Induced Intestinal Ulcerogenic Lesions in Adjuvant-Induced Arthritis Rat
}

\author{
Noriaki Nagai, ${ }^{* a}$ Tadatoshi Tanino, ${ }^{b}$ and Yoshimasa Ito ${ }^{a}$ \\ ${ }^{a}$ Faculty of Pharmacy, Kinki University; 3-4-1 Kowakae, Higashi-Osaka, Osaka 577-8502, Japan: and ${ }^{b}$ Faculty of \\ Pharmaceutical Sciences, Tokushima Bunri University; 180 Yamashiro-cho, Tokushima, Tokushima 770-8514, Japan. \\ Received April 28, 2015; accepted June 8, 2015
}

It is well known that rheumatoid arthritis patients taking nonsteroidal anti-inflammatory drugs (NSAIDs) are more susceptible to NSAIDs-induced gastroenteropathy in comparison with other patients. In this study we demonstrate that expression levels of interleukin (IL)-18 are related to aggravation of intestinal ulcerogenic lesions in adjuvant-induced arthritis (AA) rats following oral administration of indomethacin. AA rats were administered oral indomethacin $(40 \mathrm{mg} / \mathrm{kg})$ and killed under deep isoflurane anesthesia after $24 \mathrm{~h}$. The small intestinal mucosa was then examined. Oral administration of indomethacin caused hemorrhagic lesions in the small intestinal mucosa of AA rats, and the lesion score of AA rats $24 \mathrm{~h}$ after indomethacin treatment was approximately 5.6-fold higher than for normal rats administered indomethacin. IL-18 expression in the small intestinal mucosa of $\mathrm{AA}$ rats administered indomethacin was also higher in comparison with normal rats receiving indomethacin. In addition, interferon- $\gamma$ and nitric oxide levels in the small intestinal mucosa of AA rats were increased following oral administration of indomethacin. It is possible that IL-18 expression in AA rats renders the small intestinal mucosa more sensitive to indomethacin, and that IL-18 may play a role in aggravating intestinal ulcerogenic lesions in AA rats treated with this drug.

Key words interleukin (IL)-18; intestinal ulcerogenic lesion; indomethacin; rheumatoid arthritis; interferon- $\gamma$

Rheumatoid arthritis (RA) is a complex chronic inflammatory disease dependent on multiple interacting genetic and environmental factors, making it difficult to find effective therapies. ${ }^{1)}$ In treatments for RA, the focus is on the reduction of inflammation, pain and joint damage. The principal pharmacological agents are nonsteroidal anti-inflammatory drug (NSAIDs), glucocorticoids and specific inhibitors of the mediator response, disease-modifying antirheumatic drugs. ${ }^{2)}$ However, it is well known that these drugs have significant side effects. ${ }^{3)}$ In the patients taking NSAIDs, gastroenteropathy is known as the most common side effect. In addition, the RA patients taking NSAIDs are more susceptible to NSAIDs-induced intestinal ulcerogenic lesions in comparison with other patients. ${ }^{3-5)}$ The formation of NSAIDs-induced intestinal ulcerogenic lesions is believed to involve the depletion of endogenous prostaglandins, and the low prostaglandins is caused by the inhibition of cyclooxygenase. ${ }^{5-7)}$ On the other hand, a number of elements, such as inducible nitric oxide synthase (iNOS), bacterial flora and neutrophils are also involved in the pathogenesis of intestinal ulceration induced by NSAIDs. ${ }^{8-12)}$ In particularly, the presence of enterobacteria is essential for NSAID-induced ulceration to occur in the small intestine. ${ }^{10,11)}$ Previously reports show that the excessive production of nitric oxide (NO) plays a key pathogenic role in the intestinal ulcerogenic response to indomethacin (IMC) in model rats for RA, and the number of intestinal ulcerogenic lesions increases with the increasing oral dose. ${ }^{3,13-15)}$ However, the pathogenic mechanism for the formation of these lesions is not fully understood.

The selection of an experimental animal is very important in the studies to identify the mechanisms of IMC-induced intestinal ulcerogenic lesions in RA. The adjuvant-induced arthritis (AA) rat is often used for the study of inflammatory pain during the development of AA is assessed by measuring paw volume (paw edema). ${ }^{16,17)}$ The paw edema in AA rats is observed the two inflammatory stages (primary and secondary inflammation). The primary inflammation starts from the day following the injection of adjuvant into the right hind foot, and the secondary inflammation is observed from $7 \mathrm{~d}$ after adjuvant injection. ${ }^{3)}$ It has been also reported that gastric and small intestinal mucosal lesions induced by IMC, aspirin, and naproxen, which is conventional NSAIDs, are significantly aggravated in AA rats as compared with normal rats. ${ }^{3,5)}$ In addition, the changes in the biological characteristics of AA rats correspond to those that occur in human RA..$^{3,5,16,17)}$ Therefore, AA rats may be an useful model for studies on the mechanisms of IMC-induced intestinal ulcerogenic lesions in RA.

Interleukin 18 (IL-18), which is a pleiotropic cytokine belonging to the IL-1 family, is expressed as an inactive 24$\mathrm{kDa}$ proform that is cleaved by caspase-1 (IL- $\beta$ converting enzyme) to an $18-\mathrm{kDa}$ active form (mature IL-18). ${ }^{18,19)}$ The mature IL-18 exerts its effects upon binding to its cognate receptor (IL-18R). ${ }^{20)}$ The IL-18R $\alpha$ and IL-18R $\beta$ were known that the two subunits of IL-18R. ${ }^{20}$ ) The IL-18R $\alpha$ have a low-affinity receptor for IL-18. ${ }^{20)}$ On the other hand, IL-18R $\beta$, the second subunit, does not bind IL-18 directly, but the $\beta$ chain increases the IL-18 binding affinity and is necessary for initiating signal transduction in target cells. ${ }^{21)}$ The binding of mature IL-18 to IL-18R leads to the production of interferon (IFN)- $\gamma^{22)}$ and iNOS. ${ }^{23)}$ IL-18 plays an important role in inflammatory action. $^{18,21)}$ Therefore, IL-18 may be related to the aggravation of NSAIDs-induced intestinal ulcerogenic lesions in RA.

In this study we investigated whether IL-18 expression is related to the aggravation of intestinal ulcerogenic lesion in IMC-administered AA rats. 


\section{MATERIALS AND METHODS}

Animals The rats used were male Dark Agouti (DA) rats aged 6 to 13 weeks provided by Shimizu Laboratory Supplies Co., Ltd. (Kyoto, Japan). They were housed under standard conditions (12 h/d fluorescent light (07:00-19:00), $25^{\circ} \mathrm{C}$ room temperature) and allowed free access to a commercial diet (CE-2, Clea Japan Inc., Osaka, Japan) and water. All animal experiments were performed in accordance with the Kinki University School of Pharmacy Committee for the Care and Use of Laboratory Animals.

Induction of Arthritis in DA Rats Arthritis was induced by the injection of $50 \mu \mathrm{L}$ of adjuvant, a suspension of $10 \mathrm{mg} /$ $\mathrm{mL}$ heat-killed Mycobacterium butyricum (Difco, Detroit, MI, U.S.A.) in Bayol F oil, into the plantar region of the right hind foot and tail of DA rats. The control group received $50 \mu \mathrm{L}$ of Bayol $\mathrm{F}$ oil. In this study, inflammation during the development of AA was assessed by measuring paw edema, which is one parameter of inflammation. Paw edema was assessed by measuring the paw volume by plethysmometry.

Evaluation of Intestinal Ulcerogenic Lesions IMC (Wako Pure Chemical Industries, Ltd., Osaka, Japan) was suspended in saline solution containing $1.0 \%$ carboxymethy cellulose (Nacalai Tesque, Kyoto, Japan). Normal rats and AA rats at 7, 14, 21, $42 \mathrm{~d}$ after adjuvant injection were orally administered IMC $(40 \mathrm{mg} / \mathrm{kg})$ once at the described day, and killed under deep isoflurane anesthesia $24 \mathrm{~h}$ later. ${ }^{3,13)}$ The jejunum $(40 \%$ of the upper part of the small intestine except the duodenum (lower $2 \mathrm{~cm}$ of the stomach), $27.2 \pm 3.6 \mathrm{~cm}$ ), and ileum $(60 \%$ of the lower part of small intestine except the duodenum, $40.7 \pm 6.5 \mathrm{~cm}$ ) were excised (mean \pm standard error (S.E.), $n=15$ ), washed and fixed in $10 \%$ formalin solution, and the area of the intestinal ulcerogenic lesions was observed in digital photographs using Image J software (NIH). The lesion area is expressed as the percentage of the total area of small intestine. In this study, no ulcerogenic lesions in the duodenum were observed with or without the administration of IMC.

RNA Preparation Total RNAs were extracted from the small intestinal mucosa (epithelium in the jejunum and ileum) of rats by the acid guanidium thiocyanate-phenol-chloroform extraction method ${ }^{24)}$ using Trizol reagent (Life Technologies Inc., Rockville, U.S.A.) according to the manufacturer's in- structions. Total cellular RNA in Caco-2 cells was extracted and purified using the RNeasy Mini Kit and RNase-Free DNase Set (Qiagen, Tokyo, Japan) according to the manufacturer's instructions.

Quantitative Real-Time Reverse Transcription Polymerase Chain Reaction (RT-PCR) The RT reaction was performed using an RNA PCR Kit (AMV Ver 3.0, TaKaRa Bio Inc., Shiga, Japan). One microgram of total RNA was mixed with $3 \mu \mathrm{L}$ of $10 \mathrm{~mm}$ Tris- $\mathrm{HCl}$ buffer ( $\mathrm{pH}$ 8.3) containing $5 \mathrm{~mm} \mathrm{MgCl}_{2}$ and $50 \mathrm{~mm} \mathrm{KCl}$. The following components were then added to give a final volume of $10 \mu \mathrm{L}$ : 1 unit $/ \mu \mathrm{L}$ RNase inhibitor, $10 \mathrm{~mm}$ deoxynucleotide triphosphate, 2.5 units $/ \mu \mathrm{L}$ reverse transcriptase, and $0.125 \mu \mathrm{M}$ oligo dT-adaptor primer. The RT reaction was performed at $42^{\circ} \mathrm{C}$ for $15 \mathrm{~min}$, followed by $5 \mathrm{~min}$ at $95^{\circ} \mathrm{C}$. The PCR reactions were performed using LightCycler FastStart DNA Master SYBR Green I according to the manufacturer's instructions (Roche Diagnostics Applied Science, Mannheim, Germany). Briefly, $2 \mu \mathrm{L}$ of cDNA was mixed with $2 \mu \mathrm{L}$ of reaction mixture, LightCycler FastStart DNA Master SYBR Green I Reaction Mix, containing FastStart Taq DNA Polymerase, reaction buffer, $\mathrm{MgCl}_{2}$, SYBR Green I dye, and deoxynucleotide triphosphate mix. Specific primers for IL-18, IL-18R $\alpha$, IL-18R $\beta$, IL-18 binding protein (IL-18BP), caspase-1, iNOS or glyceraldehyde-3-phosphate dehydrogenase (GAPDH) (10 pmol each) were then added to give a final volume of $20 \mu \mathrm{L}$. The primers used are summarized in Table 1, and the conditions for PCR are shown in Table 2. In addition, in the study using Caco-2 cells, the following primers were used: 5'-CCA AGA GAA GAG AGA TTC CAT TGA A-3' and 5'-TGA TTT TCC TGT CTC TGT CGC A-3' for iNOS; and 5'-TGC ACC ACC AAC TGC TTA GC-3' and 5'-GGC ATG GAC TGT GGT CAT GAG-3' for GAPDH. The conditions for PCR were: $95^{\circ} \mathrm{C}$ for $10 \mathrm{~min}, 50$ cycles of $95^{\circ} \mathrm{C}$ for $10 \mathrm{~s}$ (denaturing), $60^{\circ} \mathrm{C}$ for $10 \mathrm{~s}$ (annealing), and $72^{\circ} \mathrm{C}$ for $5 \mathrm{~s}$ (extension). The quantities of PCR products were measured fluorometrically in a real-time manner using a LightCycler DX 400 (Roche Diagnostics Applied Science). After the completion of the PCR reactions, dissociation curves of the PCR products were generated using the LightCycler Software Version 4.0 program to detect nonspecific amplification, including primer-dimers, and to ascertain the quality of the amplification data. The differences in the threshold cycles for GAPDH and other groups (IL-18, IL-18R $\alpha$, IL-18R $\beta$, IL-

Table 1. Sequences of Primers Used for Quantitative RT-PCR Analysis

\begin{tabular}{|c|c|c|c|}
\hline Primer & & Sequence $\left(5^{\prime}-3^{\prime}\right)$ & GenBank accession No. \\
\hline \multirow[t]{2}{*}{ IL-18 } & FOR & CGCAGTAATACGGAGCATAAATGAC & NM_019165 \\
\hline & REV & GGTAGACATCCTTCCATCCTTCAC & \\
\hline \multirow[t]{2}{*}{ IL-18R $\alpha$} & FOR & AGCAGAAAGAGACGAGACACTAAC & XM_237088 \\
\hline & REV & CTCCACCAGGCACCACATC & \\
\hline \multirow[t]{2}{*}{ IL-18R $\beta$} & FOR & GACCACAGGATTTAACCATTCAGC & AJ550893 \\
\hline & REV & AGCAGGACCTAGTGTTGATGATG & \\
\hline \multirow[t]{2}{*}{ IL-18BP } & FOR & TTGGTGGGTCCTGCTTCTATATG & AF154569 \\
\hline & REV & GGTCAGCGTTCCATTCAGTG & \\
\hline \multirow[t]{2}{*}{ Caspase-1 } & FOR & TGAAGATGATGGCATTAAGAAGGC & NM_012762 \\
\hline & REV & CAAGTCACAAGACCAGGCATATTC & \\
\hline \multirow[t]{2}{*}{ iNOS } & FOR & GGAGAGATTTTTCACGACACCC & NM_012611 \\
\hline & REV & CCATGCATAATTTGGACTTGCA & \\
\hline \multirow[t]{2}{*}{ GAPDH } & FOR & ACGGCACAGTCAAGGCTGAGA & NM_017008 \\
\hline & REV & CGCTCCTGGAAGATGGTGAT & \\
\hline
\end{tabular}


Table 2. Parameters Used for Quantitative RT-PCR Analysis

\begin{tabular}{lccc}
\hline \hline Primer & Hot start $(10 \mathrm{~min})$ & Denaturation $(10 \mathrm{~s})$ & Annealing $(10 \mathrm{~s})$ \\
\hline IL-18 & $95^{\circ} \mathrm{C}$ & $95^{\circ} \mathrm{C}$ & $53^{\circ} \mathrm{C}$ \\
IL-18R $\alpha$ & $95^{\circ} \mathrm{C}$ & $95^{\circ} \mathrm{C}$ & $57^{\circ} \mathrm{C}$ \\
IL-18R $\beta$ & $95^{\circ} \mathrm{C}$ & $95^{\circ} \mathrm{C}$ & $72^{\circ} \mathrm{C}$ \\
IL-18BP & $95^{\circ} \mathrm{C}$ & $95^{\circ} \mathrm{C}$ & $53^{\circ} \mathrm{C}$ \\
Caspase-1 & $95^{\circ} \mathrm{C}$ & $95^{\circ} \mathrm{C}$ & $55^{\circ} \mathrm{C}$ \\
iNOS & $95^{\circ} \mathrm{C}$ & $95^{\circ} \mathrm{C}$ & $72^{\circ} \mathrm{C}$ \\
GAPDH & $95^{\circ} \mathrm{C}$ & $95^{\circ} \mathrm{C}$ & $72^{\circ} \mathrm{C}$ \\
\end{tabular}

18BP, caspase-1 and iNOS) were used to calculate the levels of mRNA expression in the rats.

Measurement of Protein Protein levels in the epithelium of the jejunum and ileum of rats were determined according to the method of Bradford ${ }^{25}$ using a Bio-Rad Protein Assay Kit (BIO-RAD, CA, U.S.A.) with bovine serum albumin as the standard.

Western Blot Analysis Samples of rat small intestinal mucosa (epithelium of the jejunum and ileum) were homogenized in saline on ice, and centrifuged at $1500 \mathrm{rpm}$ for $10 \mathrm{~min}$ at $4{ }^{\circ} \mathrm{C}$. The resultant supernatants were suspended in buffer comprising $1.25 \mathrm{mmol} / \mathrm{L}$ Tris- $\mathrm{HCl}, \mathrm{pH} 6.8,0.4 \%$ sodium dodecyl sulfate (SDS), $0.2 \%$ glycerol, $0.1 \%$ 2-mercaptoethanol and $0.004 \%$ bromophenol blue, and boiled for $3 \mathrm{~min}$. A sample of total protein $(20 \mu \mathrm{g})$ was separated in a $15 \%$ polyacrylamide SDS gel, and the proteins were transferred to polyvinylidene difluoride membranes (BIO-RAD) using a semi-dry transfer cell (Trans-Blot SD Semi-Dry Electrophoretic Transfer Cell, BIO-RAD). The transfer buffer used in the system contained $25 \mathrm{mmol} / \mathrm{L}$ Tris- $\mathrm{HCl}, 191 \mathrm{mmol} / \mathrm{L}$ glycine, $20 \%$ methanol, and $0.0375 \%$ SDS. After transfer, nonspecific sites on the membranes were blocked with $5 \%$ non-fat dry milk in Trisbuffer $(20 \mathrm{mmol} / \mathrm{L}$ Tris $-\mathrm{HCl}$, and $500 \mathrm{mmol} / \mathrm{L} \mathrm{NaCl}, \mathrm{pH} 7.5)$. The blots were probed with $0.31 \mathrm{mg} / \mathrm{L}$ goat anti-rat IL-18 polyclonal antibody (Promega, WI, U.S.A.) or with $0.17 \mathrm{mg} / \mathrm{L}$ rabbit anti-rat GAPDH polyclonal antibody (IMGENEX, CA, U.S.A.) for $2 \mathrm{~h}$ at room temperature. The membrane was then washed with Tris-buffer containing $0.05 \%$ Tween 20 , and incubated with secondary antibody, alkaline-phosphatase conjugated anti-goat immunoglobulin G (IgG) (1:7000 dilution, Promega) or alkaline-phosphatase conjugated anti-rabbit $\operatorname{IgG}(1: 7000$ dilution, Promega), for $2 \mathrm{~h}$ at room temperature, washed with Tris-buffer containing $0.1 \%$ Tween 20, and incubated with a stabilized substrate for alkaline phosphatase (Promega).

Measurement of IL-18 Levels Samples of rat small intestinal mucosa (epithelium of the jejunum and ileum) were homogenized in purified water, and centrifuged at $1500 \mathrm{rpm}$ for $10 \mathrm{~min}$ at $4^{\circ} \mathrm{C}$. The supernatants were used for the measurement of IL-18 levels using an Endogen ${ }^{\circledR}$ Rat IL-18 ELISA Kit according to the manufacturer's instructions (Invitrogen Camarillo, CA, U.S.A.). Briefly, monoclonal antibodies specific for rat IL-18 were pre-coated onto microplates. Standards and samples were pipetted into the wells, and the microplates were incubated at room temperature for $2 \mathrm{~h}$. After washing to remove unbound materials, biotinylated antibodies were added to the wells. After washing, streptavidin-horseradish peroxidase (HRP) solutions were added, and the wells were washed to remove unbound materials after which the substrates were added. The enzyme reactions yielded blue products that turned yellow when the stop solutions were added. Absorbance at $450 \mathrm{~nm}$ was measured with a microplate reader (BIO-RAD). The range of detection for IL-18 was $15.6-1000 \mathrm{pg} / \mathrm{mL}$, and the IL-18 levels in this study were within the detection range.

Measurement of IFN- $\boldsymbol{\gamma}$ Levels Samples of rat small intestinal mucosa (epithelium of the jejunum and ileum) were homogenized in purified water, and centrifuged at $1500 \mathrm{rpm}$ for $10 \mathrm{~min}$ at $4^{\circ} \mathrm{C}$. The resultant supernatants were used for the measurement of IFN- $\gamma$ levels. The IFN- $\gamma$ levels were measured using Endogen ${ }^{\circledR}$ Rat IFN $\gamma$ ELISA kits according to the manufacturer's instructions (Pierce Biotechnology Inc., WI, U.S.A.). Briefly, monoclonal antibodies specific for rat IFN- $\gamma$ were pre-coated onto microplates, standards and samples were pipetted into the wells, and the microplates were incubated at room temperature for $1 \mathrm{~h}$. After washing to remove unbound materials, biotinylated antibodies were added to the wells. After washing, streptavidin-HRP solutions were added, and the wells were washed to remove unbound materials. Then the substrates were added. The enzyme reactions yielded blue products that turned yellow when the stop solutions were added. The absorbance at $450 \mathrm{~nm}$ was measured with a microplate reader (BIO-RAD). The range of detection for IFN- $\gamma$ was $8-500 \mathrm{pg} / \mathrm{mL}$, and the IFN- $\gamma$ levels in this study were within detection range.

Measurement of NO Levels Samples of rat small intestinal mucosa (epithelium of the jejunum and ileum) were homogenized in saline on ice, and centrifuged at $10000 \mathrm{rpm}$ for $15 \mathrm{~min}$ at $4^{\circ} \mathrm{C}$. The resultant supernatants were used for the measurement of NO levels. In addition, treated and untreated Caco-2 cells were cultured in medium, which was then collected in a tube. A concentric microdialysis probe (A-1-20-05, $5 \mathrm{~mm}$ length; Eicom, Kyoto, Japan) was placed in the supernatant or medium, and perfused with Ringer's solution (140 $\mathrm{mm} \mathrm{NaCl}, 4 \mathrm{~mm} \mathrm{KCl}, 1.26 \mathrm{~mm} \mathrm{CaCl}_{2}$, and $1.15 \mathrm{~mm} \mathrm{MgCl}_{2}$, $\mathrm{pH}$ 7.4) at a constant flow rate of $2 \mu \mathrm{L} / \mathrm{min}$ using a micro syringe pump (ESP-64, Eicom). $\mathrm{NO}_{2}^{-}$and $\mathrm{NO}_{3}^{-}$in the supernatants or medium were separated on a reverse-phase separation column packed with polystyrene polymer (NO-PAK, $4.6 \times 50 \mathrm{~mm}$, Eicom); $\mathrm{NO}_{3}^{-}$was reduced to $\mathrm{NO}_{2}^{-}$in a reduction column packed with copper-plated cadmium filings (NO-RED, Eicom). $\mathrm{NO}_{2}^{-}$was mixed with Griess reagent to form a purple azo dye in a reaction coil, which was placed in a column oven set at $35^{\circ} \mathrm{C}$. The absorbance of the colored product dye at $540 \mathrm{~nm}$ was measured in a flow-through spectrophotometer (NOD-10, Eicom). The mobile phase consisted of 10\% methanol containing $0.15 \mathrm{M} \mathrm{NaCl}-\mathrm{NH}_{4} \mathrm{Cl}$ and $0.5 \mathrm{~g} / \mathrm{L} \mathrm{Na} \mathrm{Na}_{4}$-ethylenediaminetetraacetic acid (EDTA) delivered by a pump at a rate of $0.33 \mathrm{~mL} / \mathrm{min}$. Griess reagent, $1.25 \% \mathrm{HCl}$ containing $5 \mathrm{~g} / \mathrm{L}$ sulfanilamide with $0.25 \mathrm{~g} / \mathrm{L} N$-naphthylethylenediamine, was delivered at a rate of $0.1 \mathrm{~mL} / \mathrm{min}$. In this paper, the amounts of 
NO reflect the level of the $\mathrm{NO}_{2}^{-}$metabolite, which is produced from $\mathrm{NO}$.

Cell Culture and Treatments The human intestinal Caco-2 cell line (Caco-2 cell) was used in this study. Caco-2 cells were cultured in Dulbecco's modified Eagle's medium (GIBCO, Tokyo, Japan) containing 10\% (v/v) heat-inactivated fetal bovine serum (DMEM) (GIBCO), 1\% non-essential amino acid solution (GIBCO), $1 \%$ L-glutamine and $10 \mu \mathrm{g} / \mathrm{mL}$ streptomycin and $1000 \mathrm{IU} / \mathrm{mL}$ penicillin (GIBCO). Cells were incubated under humidified air containing $5 \% \mathrm{CO}_{2}$ at $37^{\circ} \mathrm{C}$. Treatments were carried out when the cells were $80 \%$ confluent, usually on the third day after seeding $\left(4.0 \times 10^{3}\right.$ cells $\left./ \mathrm{cm}^{2}\right)$. The culture medium was changed every other day and then $1 \mathrm{~h}$ before each experiment. In the experiments, Caco-2 cells were treated with or without IFN- $\gamma$ (1000IU) and lipopolysaccharide (LPS) $(100 \mathrm{ng} / \mathrm{mL})$ for $24 \mathrm{~h}^{26)}$ For treatment with aminoguanidine, Caco- 2 cells were coincubated with LPS and IFN- $\gamma$ for $18 \mathrm{~h}$, and then $250 \mu \mathrm{M}$ aminoguanidine was added and the cells were cultured for a further $6 \mathrm{~h}$.

Statistical Analysis All values are expressed as the mean \pm standard error of the mean (S.E.M.). Statistical differences were evaluated by one-way ANOVA followed by Dunnett's multiple comparison. The $p$ values less than 0.05 were considered significant. The number of experiments performed is given in the figure legends.
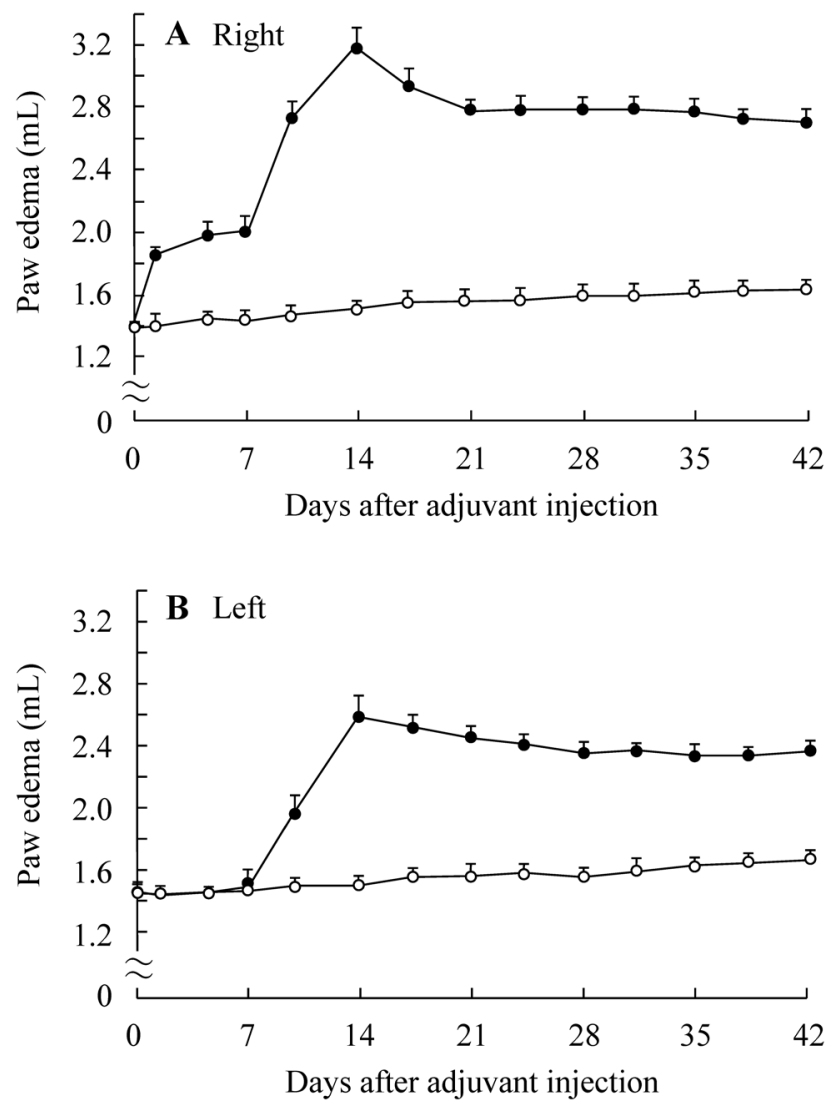

Fig. 1. Changes in Paw Volume of the Right (A) and Left (B) Hind Feet of AA Rats

Arthritis was induced by the injection of $50 \mu \mathrm{L}$ of adjuvant, a suspension of $10 \mathrm{mg} / \mathrm{mL}$ heat-killed Mycobacterium butyricum in Bayol F oil, into the plantar region of the right hind foot and tail of DA rats. Open circles, normal rats without IMC administration; closed circles, AA rats without IMC administration. The data are presented as mean \pm S.E. of 6 rats.

\section{RESULTS}

Adverse Effect of IMC on Intestinal Ulcerogenic in AA Rats Figure 1 shows the changes in paw edema in the right (A) and left (B) hind feet of rats injected with adjuvant. In the both of right hind foot injected with adjuvant and left hind foot, which was not injected with adjuvant, the paw edema reached a maximum $14 \mathrm{~d}$ after injection. Figure 2 shows the changes in the intestinal ulcerogenic response to IMC in AA rats $7-42 \mathrm{~d}$ after adjuvant injection. At 7, 21 and $42 \mathrm{~d}$ after adjuvant injection, the lesion area in the small intestinal mucosa of AA rats following the administration of IMC did not differ significantly from that in normal rats. However, at $14 \mathrm{~d}$ after adjuvant injection, the oral administration of IMC resulted in significant hemorrhagic lesions in the small intestinal mucosa of AA rats. Figure 3 shows effect of IMC on intestinal ulcerogenic in normal and AA rat $14 \mathrm{~d}$ after adjuvant injection. The lesion score of AA rats was significantly higher than that of normal rats in the jejunum and ileum. Furthermore, the ulcerogenic lesion area of the jejunal mucosa was approximately 1.7-fold higher than that of the ileal mucosa in IMC-administered AA rats.

Expression of IL-18 and IFN- $\gamma$ in the Small Intestinal Mucosa of IMC-Administered AA Rats Figure 4 shows
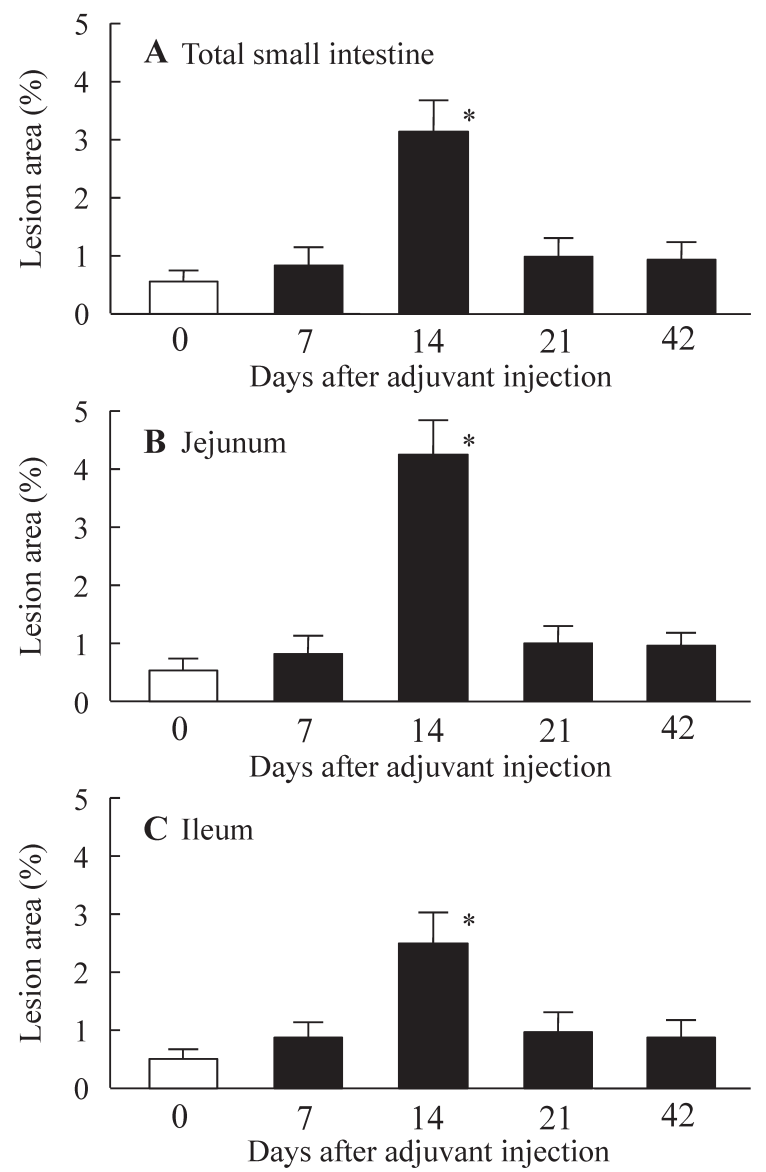

Fig. 2. Intestinal Ulcerogenic Effect of IMC in AA Rats

Normal rats without adjuvant injection $(0 \mathrm{~d})$ and $\mathrm{AA}$ rats at $7,14,21$ and $42 \mathrm{~d}$ after adjuvant injection were orally administered IMC $(40 \mathrm{mg} / \mathrm{kg})$ once at the described day, killed $24 \mathrm{~h}$ later, and the lesion areas of the total small intestine (A), jejunum (B) and ileum (C) were determined as described in Materials and Methods. Open columns: normal rats; closed columns: AA rats. The data are presented as mean \pm S.E. of $6-15$ independent rats. ${ }^{*} p<0.05 v s$. normal rats (open column). 

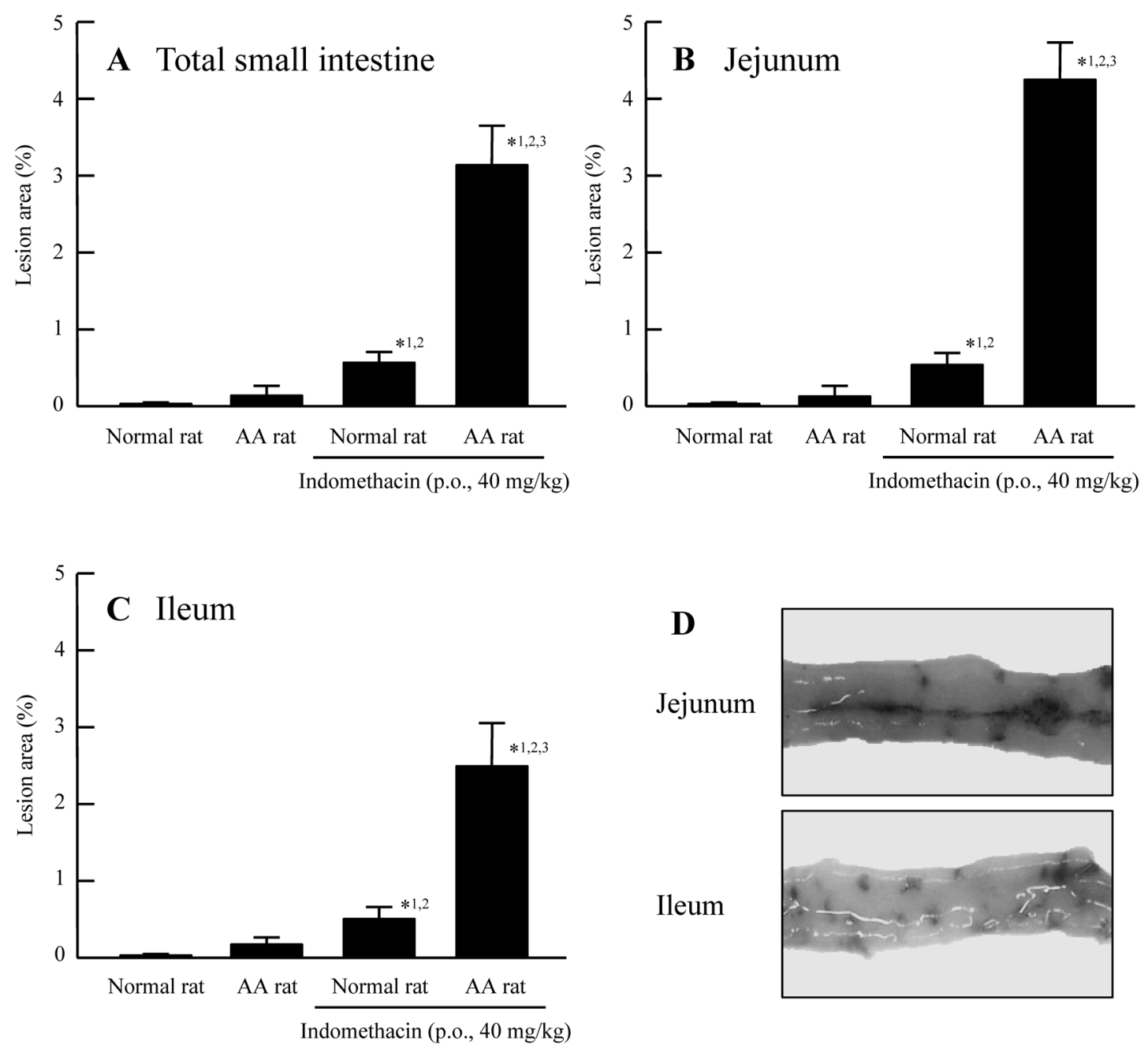

Fig. 3. Intestinal Ulcerogenic Lesions in the Jejunum and Ileum of AA Rat Administered IMC

AA and normal rats $14 \mathrm{~d}$ after adjuvant or vehicle injection were administered IMC $(40 \mathrm{mg} / \mathrm{kg})$ orally, and killed $24 \mathrm{~h}$ later. The data are presented as mean \pm S.E. of 6-15 rats. A-C: lesion scores of total small intestine (A), jejunum (B) and ileum (C) of IMC-administered AA rats. D: intestinal images of the jejunum and ileum of IMCadministered AA rats. ${ }^{* 1} p<0.05, v s$. normal rats. ${ }^{* 2} p<0.05, v s$. AA rats. ${ }^{3} p<0.05$, vs. IMC-administered normal rats.

the gene expression for IL-18 (A), IL-18R $\alpha$ (B), IL-18R $\beta$ (C), IL-18BP (D) and caspase-1 (E) in the small intestinal mucosa of normal and AA rats with or without the administration of IMC. The IL-18, IL-18R and caspase-1 mRNA levels in the jejunal and ileal mucosa of AA rats were somewhat higher than in normal rats. On the other hand, the gene expression levels in both normal and AA rats were elevated by the administration of IMC, and the mRNA levels in IMC-administered AA rats were significantly higher than IMC-administered normal rats. In addition, the levels of gene expression in the jejunal mucosa were higher than those in the ileal mucosa. Figure 5 shows the expression of mature IL-18 in IMC-administered normal and AA rats as determined by the Western blot analysis. The mature IL-18 expression in the jejunal and ileal mucosa of IMC-administered AA rats was higher than that in IMC-administered normal rats. Figure 6 shows the IL-18 (A, B) and IFN- $\gamma(\mathrm{C}, \mathrm{D})$ levels in IMC-administered normal and AA rats. The IL-18 and IFN- $\gamma$ levels in the small intestinal mucosa of AA rats were also increased by the administration of IMC, and the levels in the jejunal mucosa were higher in comparison with those in the ileal mucosa.

Expression of NO Levels in the Small Intestinal Mucosa of IMC-Administered AA Rats Figure 7 shows iNOS gene expression (A, B) and $\mathrm{NO}$ levels $(\mathrm{C}, \mathrm{D})$ in the small intestinal mucosa of IMC-administered normal and AA rats. The iNOS mRNA and NO levels increased in the small intestinal mucosa of IMC-administered normal and AA rats The increases of iNOS mRNA and NO levels in AA rats were significantly higher than in normal rats, as well as higher in the jejunal mucosa than in the ileal mucosa. On the other hand, a close relationship was observed among IL-18, IFN- $\gamma$ and NO production (Fig. 8). Figure 9 shows the changes in the levels of IL-18, IFN- $\gamma$, and $\mathrm{NO}$, as well as the area of intestinal ulcerogenic lesions in the jejunum and ileum of AA rat $0-24 \mathrm{~h}$ after the administration of IMC. The expression levels of IL-18, IFN- $\gamma$, and $\mathrm{NO}$ in the jejunum and ileum of AA rat were observed at 6,12 , and $18 \mathrm{~h}$ after the administration of IMC. In addition, the increase in the area of intestinal ulcerogenic lesions in IMC-administered AA rats began after the increases in the IL-18, IFN- $\gamma$, and NO levels.

Effect of IFN- $\gamma$ on NO Production in the Human Intestinal Caco-2 Cell Line Treated with LPS Figure 10 shows the expressions of the iNOS mRNA and NO in Caco-2 cells treated with or without LPS and IFN- $\gamma$. Although the expression of the iNOS mRNA was increased by treatment with IFN- $\gamma$ or LPS alone, no NO release was observed. On the con- 

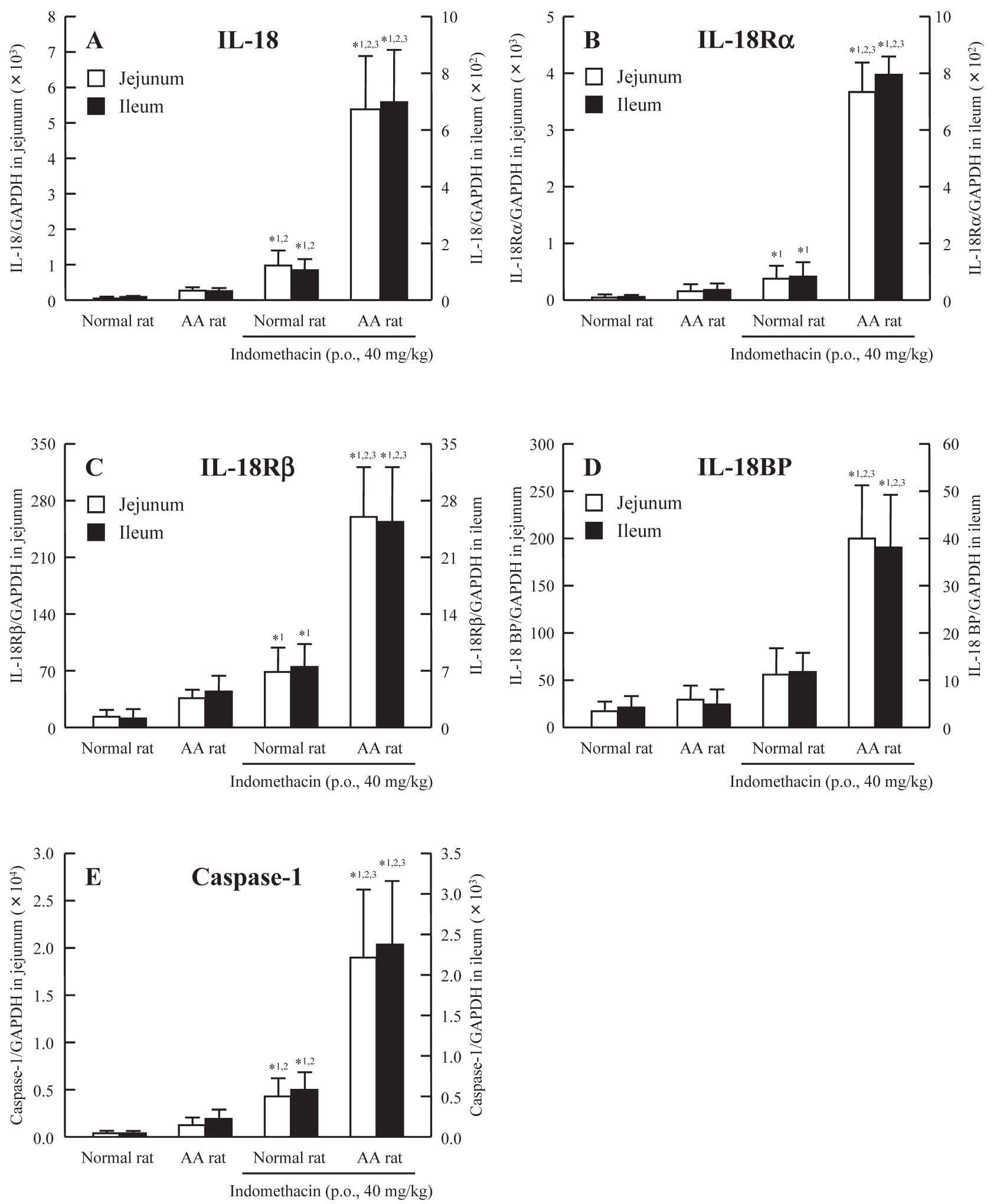

Fig. 4. Expression Levels of the mRNAs for IL-18 (A), IL-18R $\alpha$ (B), IL-18R $\beta$ (C), IL-18BP (D) and Caspase-1 (E) in the Small Intestinal Mucosa of AA Rats Administered IMC

AA and normal rats $14 \mathrm{~d}$ after adjuvant or vehicle injection were administered IMC $(40 \mathrm{mg} / \mathrm{kg})$ orally, and killed $24 \mathrm{~h}$ later. mRNA expression levels were determined by the quantitative real-time RT-PCR method. Open columns: jejunum; closed columns: ileum. The data are presented as mean \pm S.E. of $5-6$ rats. $* 1 p<0.05$, $v$. normal rats. $*^{2} p<0.05, v s$. AA rats. ${ }^{3} p<0.05, v s$. IMC-administered normal rats.

trary, treating Caco-2 cells with a combination of LPS and IFN- $\gamma$ induced iNOS mRNA expression and NO release. In addition, aminoguanidine significantly attenuated the release of NO in Caco- 2 cells treated with a combination of LPS and IFN- $\gamma$.

\section{DISCUSSION}

In this study, we investigated whether the excessive expression of IL-18 relates to the aggravation of intestinal ulcerogen- 

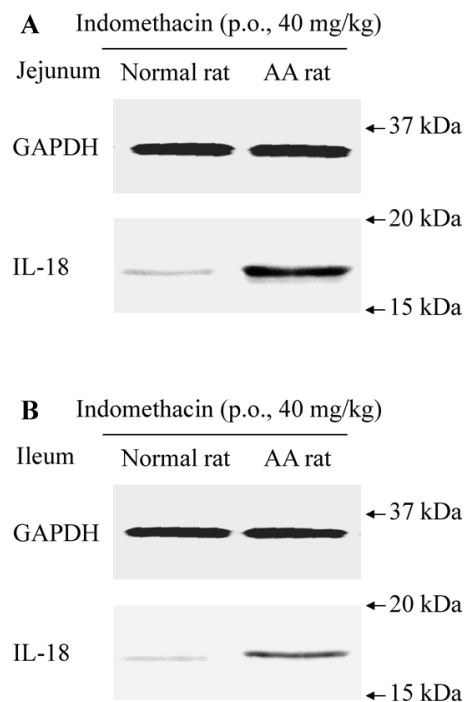

Fig. 5. Appearance of the Mature IL-18 Protein in the Small Intestinal Mucosa of AA Rats Administered IMC

A, jejunum; B, ileum. AA rats $14 \mathrm{~d}$ after adjuvant injection were administered IMC $(40 \mathrm{mg} / \mathrm{kg})$ orally, and killed $24 \mathrm{~h}$ later. The mature IL-18 protein was detected by Western blot analysis.
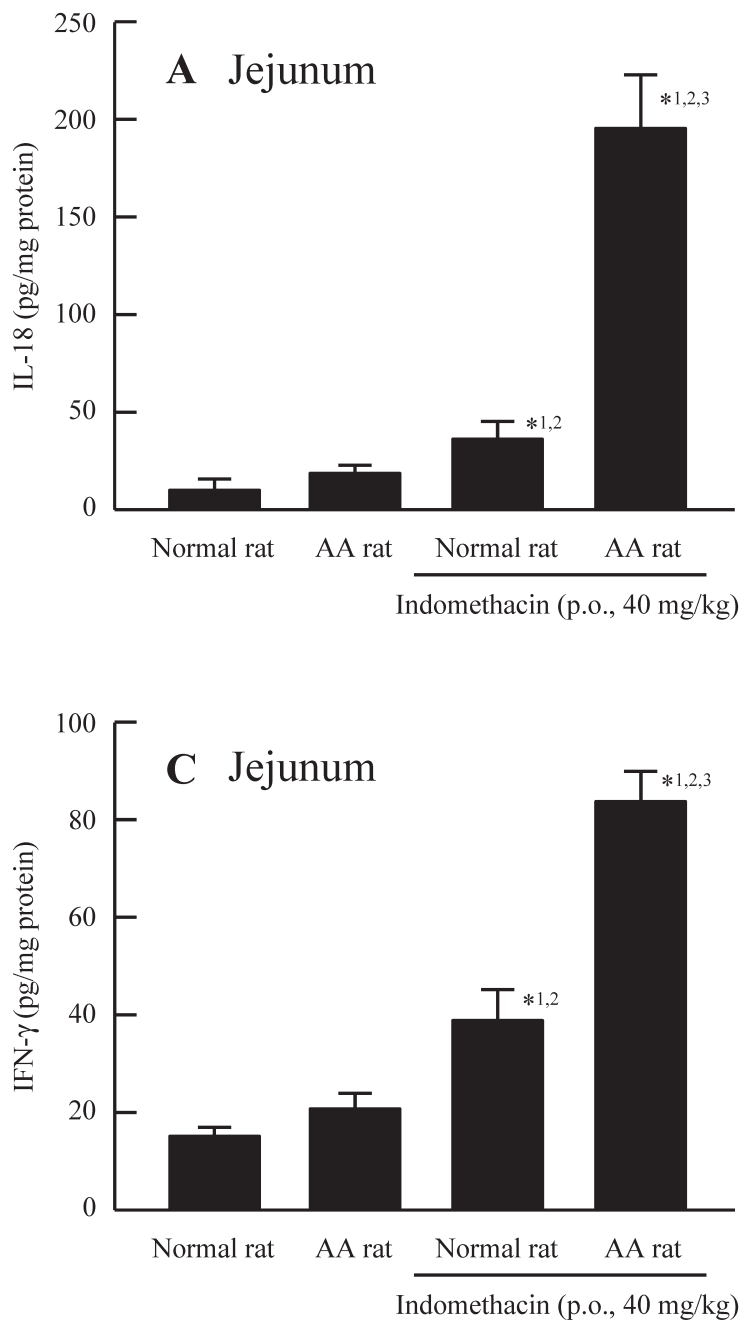

ic lesions in IMC-administered AA rats, and found that the IL-18 plays a role in the aggravation of intestinal ulcerogenic lesions in AA rats oral administered with IMC.

It has been reported that patients with RA are more susceptible to NSAIDs-induced intestinal ulcerogenic lesions than other NSAIDs users. ${ }^{3-5,17)}$ Furthermore, it is well known that IMC has significant gastrointestinal toxicity as its main adverse effect. Therefore, we demonstrate the gastrointestinal toxicity in IMC-administered AA rats. The oral administration of IMC caused hemorrhagic lesions in the jejunal and ileal mucosa of AA rats $14 \mathrm{~d}$ after adjuvant injection, with a lesion score in the total small intestine of AA rats $24 \mathrm{~h}$ after IMC administration approximately 5.6-fold higher than for normal rats also administered IMC (Fig. 3).

Next, we investigate that the gene expression of the IL-18 in the jejunal and ileal mucosa of IMC-administered normal and AA rats. The IL-18, IL-18R and caspase- 1 mRNA expression and mature IL-18 levels in the jejunal and ileal mucosa of IMC-administered AA rats were higher than that in IMCadministered normal rats (Figs. 4-6), as was the IFN- $\gamma$ level (Fig. 6). These results suggest that the expressions of mature IL-18 in the jejunal and ileal mucosa of AA rat are more sensitive to IMC. On the other hand, the gene expression of IL-
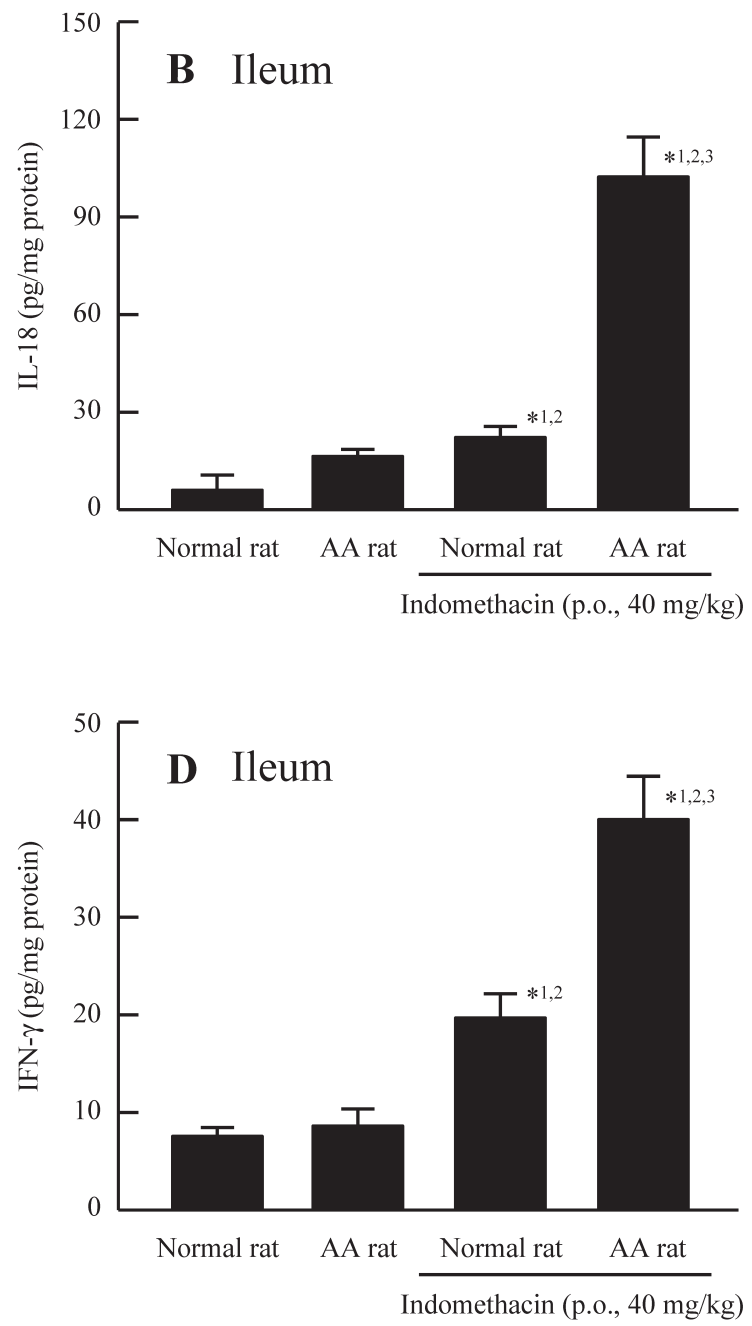

Fig. 6. Changes in IL-18 and IFN- $\gamma$ Levels in the Small Intestinal Mucosa of AA Rats Administered IMC

A and B: IL-18 levels in jejunum (A) and ileum (B) of IMC-administered AA rats. C and D: IFN- $\gamma$ levels in jejunum (C) and ileum (D) of IMC-administered AA rats. $\mathrm{AA}$ and normal rats $14 \mathrm{~d}$ after adjuvant or vehicle injection were administered IMC $(40 \mathrm{mg} / \mathrm{kg})$ orally, and killed $24 \mathrm{~h}$ later. IL-18 and IFN- $\gamma$ levels were determined using an ELISA method. The data are presented as mean \pm S.E. of 6 rats. ${ }^{* 1} p<0.05$, vs. normal rats. ${ }^{* 2} p<0.05$, $v$. AA rats. ${ }^{* 3} p<0.05$, $v s$. IMC-administered normal rats. 

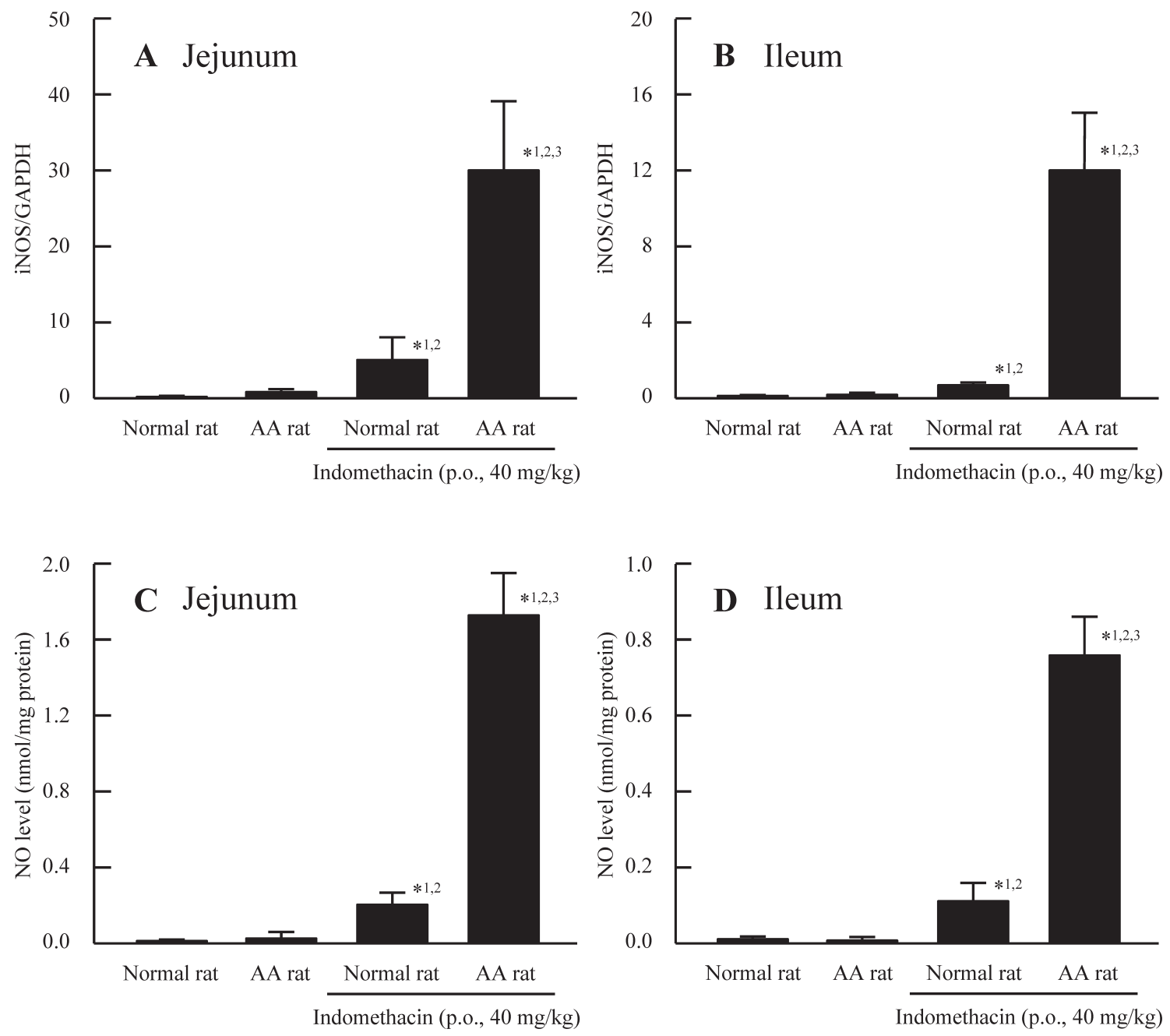

Fig. 7. Changes in iNOS mRNA and NO Levels in the Small Intestinal Mucosa of AA Rats Administered IMC

A and B: Expression of iNOS mRNA in jejunum (A) and ileum (B) of IMC-administered AA rats. C and D: NO levels in jejunum (C) and ileum (D) of IMC-administered AA rats. AA and normal rats $14 \mathrm{~d}$ after adjuvant or vehicle injection were administered IMC $(40 \mathrm{mg} / \mathrm{kg})$ orally, and killed $24 \mathrm{~h}$ later. The iNOS mRNA expression level was determined using the quantitative real-time RT-PCR method, and NO levels were measured by a microdialysis method. The data are presented as mean \pm S.E. of 6 independent rat. ${ }^{* 1} p<0.05$, vs. normal rat. ${ }^{* 2} p<0.05$, vs. AA rat. ${ }^{* 3} p<0.05$, vs. IMC-administered normal rat.

18BP, a protein that inhibits the activation of IL-18, ${ }^{27,28)}$ also increased in the jejunal and ileal mucosa of IMC-administered AA rats. It was reported that the elevation in IL-18BP expression is induced by IFN- $\gamma{ }^{29}$ ) Therefore, the elevation of IL18BP mRNA in the jejunal and ileal mucosa of IMC-administered AA rats may be caused by IFN- $\gamma$ production through the induction of IL-18 activation.

The pathogenic mechanism for the formation of these lesions is not fully understood, however, it was reported that enterobacterial products such as endotoxin (lipopolysaccharide (LPS)) enhance intestinal permeability by increasing the expression of iNOS. ${ }^{30)}$ In addition, Whittle et al. ${ }^{11)}$ and Konaka et $a{ }^{12)}$ further showed that the excessive NO via iNOS may also play a key pathogenic role in the ulcerogenic response. Tanaka et $a{ }^{31)}$ also reported that the oral administration of aminoguanidine, a selective inhibitor of iNOS, prevented the development of IMC-induced intestinal ulcerogenic lesions in AA rats. These reports suggest that the release of LPS contributes to NSAID-induced intestinal ulceration via the upregulation of iNOS/NO. We have also demonstrated that high levels of iNOS mRNA expression and NO production occur in the intestinal ulcerogenic lesions of IMC-administered AA rats (Fig. 7). It has been reported that two positions on the macrophage iNOS gene promoter region comprising a nuclear factor- $\kappa \mathrm{B}(\mathrm{NF}-\kappa \mathrm{B})$ binding site and IFN- $\gamma$-activated site (GAS) are necessary for iNOS induction in response to LPS/IFN$\gamma^{32,33)}$ In addition, it is known that the mature IL-18 leads to the production of IFN- $\gamma$, and that IFN- $\gamma$ induces excessive NO production by iNOS. ${ }^{34-36)}$ In this study, enhancements in IL-18 and IFN- $\gamma$ were observed before the increase in NO levels (Fig. 9) in IMC-administered AA rats, and a close relationship was observed between IL-18, IFN- $\gamma$ and NO production (Fig. 8). Moreover, we show that the combination of LPS and IFN- $\gamma$ enhances NO production via iNOS in the intestinal Caco-2 cell line (Fig. 10). Taking these findings together, we hypothesis that IFN- $\gamma$ generated by activated IL-18 may enhance the production of excessive NO via iNOS in the jejunal and ileal mucosa of IMC-administered AA rats, and that the enhancement of NO by IL-18 aggravates the formation of intestinal ulcerogenic lesions in IMC-administered AA rats (Chart 1).

On the other hand, the expressions of IL-18, IFN- $\gamma$, and iNOS mRNA as well as NO production in IMC-administered normal rats also increase as compared with rats not treated with IMC. However, the enhancements in IMC-administered 

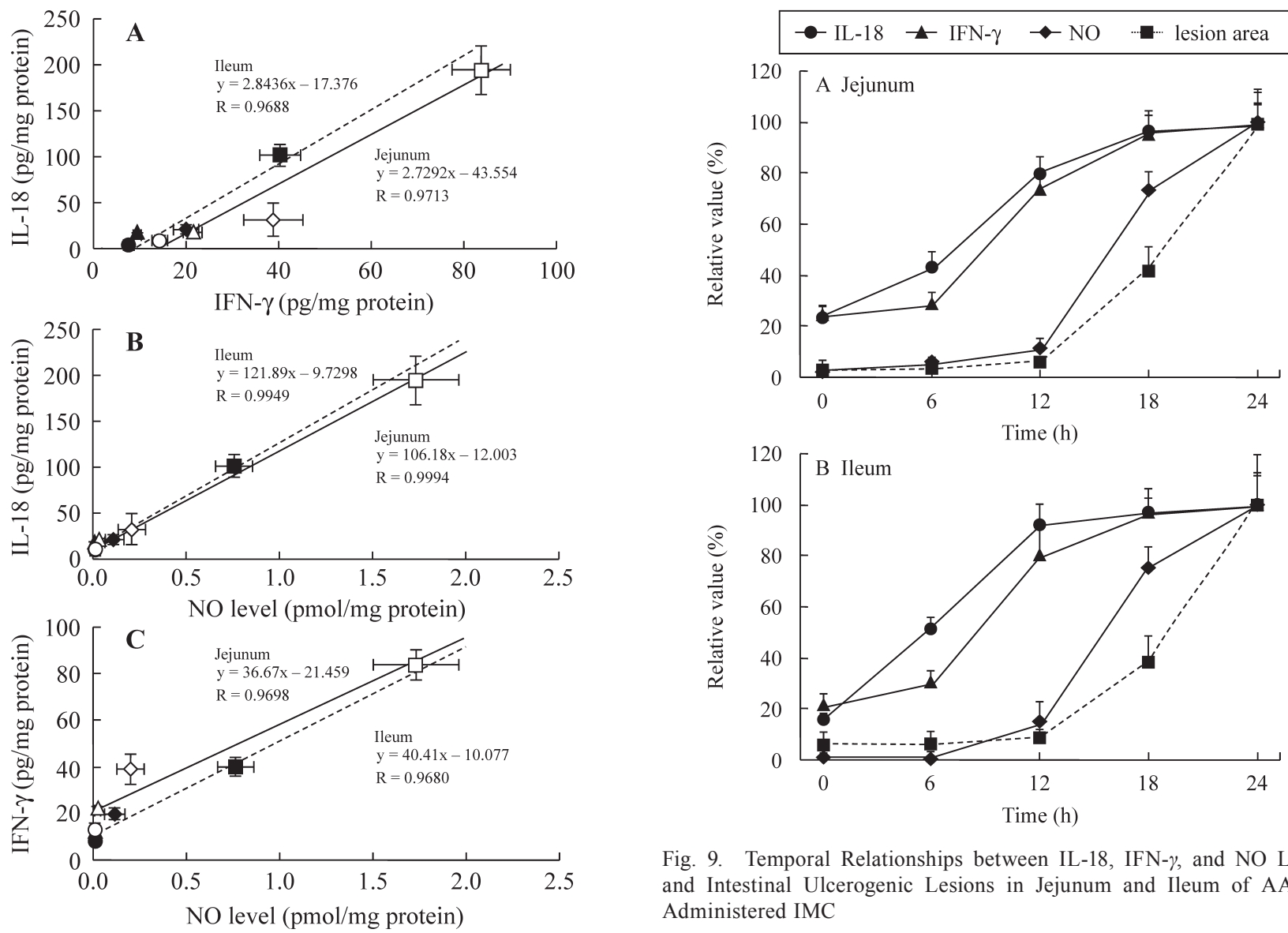

Fig. 9. Temporal Relationships between IL-18, IFN- $\gamma$, and NO Levels and Intestinal Ulcerogenic Lesions in Jejunum and Ileum of AA Rat Administered IMC

AA rats $14 \mathrm{~d}$ after adjuvant or vehicle injection were administered IMC $(40 \mathrm{mg}$ / $\mathrm{kg}$ ) orally, and killed 6-24h later. IL-18 levels (circles) and IFN- $\gamma$ levels (triangles) were determined using ELISA methods. NO levels (diamonds) were measured by a microdialysis method. Intestinal ulcerogenic lesions (squares) were observed in digital photographs and analyzed with Image J. For each parameter, the highest value attained was taken as $100 \%$. The data are presented as mean \pm S.E. of $5-6$ rats.

AA, relationship between IL-18 and IFN- $\gamma$ levels; B, relationship between IL-18 and NO levels; C, relationship between IFN- $\gamma$ and NO levels. AA and normal rats $14 \mathrm{~d}$ after adjuvant or vehicle injection were administered IMC $(40 \mathrm{mg} / \mathrm{kg})$ orally, and killed 24h later. Open symbols: jejunum; closed symbols, ileum. Normal rat (circles), AA rats (triangles), IMC-administered normal rats (diamonds) and IMC administered AA rats (squares). The data are presented as mean \pm S.E. of 6 rats.

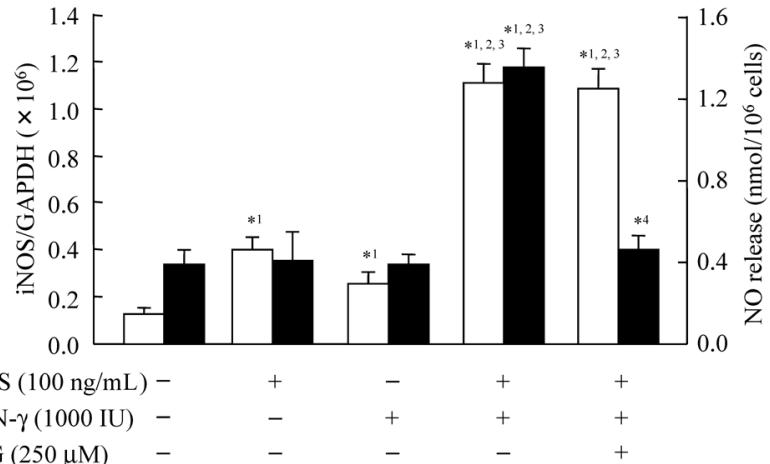

Fig. 10. Changes in iNOS mRNA Expression and NO Release in Caco-2 Cells Stimulated with or without IFN- $\gamma$ and LPS

Caco- 2 cells were treated with or without IFN- $\gamma(1000 \mathrm{IU})$ and LPS $(100 \mathrm{ng} / \mathrm{mL})$ for $24 \mathrm{~h}$. For treatment with aminoguanidine (AG), Caco-2 cells were coincubated with LPS and IFN $-\gamma$ for $18 \mathrm{~h}$, and then aminoguanidine $250 \mu \mathrm{m}$ was added and the cells were cultured for a further $6 \mathrm{~h}$. mRNA expression levels were determined by a quantitative real-time RT-PCR method, and NO levels were measured by a microdialysis method. Open columns: iNOS mRNA expression; closed columns: NO release. The data are presented as mean \pm S.E. of 8 experiments. ${ }^{* 1} p<0.05$, vs. unstimulated Caco- 2 cells. ${ }^{* 2} p<0.05$, vs. LPS-stimulated Caco-2 cells. ${ }^{* 3} p<0.05$, vs. IFN- $\gamma$-stimulated Caco-2 cells. ${ }^{* 4} p<0.05, v s$. LPS and IFN- $\gamma$-costimulated Caco-2 cells.

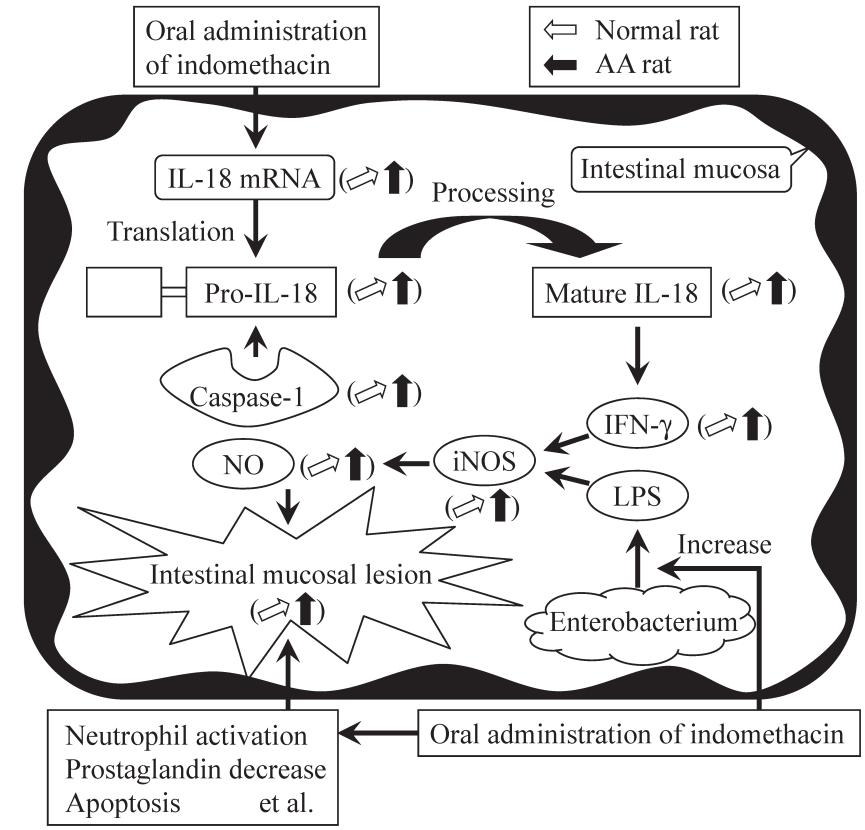

Chart 1. Chart for the Proposed Relationship between IL-18 and IMCInduced Lesions in the Small Intestinal Mucosa of Normal and AA Rats 
normal rats are much lower in comparison with IMC-administered AA rats. Therefore, the values in IMC-administered normal rats may not reach the threshold needed to aggravate intestinal ulcerogenic lesions.

It is important to clarify the localization of IL-18, IFN- $\gamma$ and iNOS in the small intestinal mucosa of arthritic rats treated with IMC. In this study, we used epithelial cell for the measurement of IL-18, IFN- $\gamma$ and iNOS. However, it has been reported that IL-18 mRNA expression is detected in a wide range of cells including Kupffer cells, macrophages, $\mathrm{T}$ cells, B cells, dendritic cells, osteoblasts, keratinocytes, astrocytes, and microglia. ${ }^{22,37,38)}$ In addition, it is known macrophages gather in inflammatory regions, and that macrophages accumulate in the small intestinal mucosa during arthritis. ${ }^{5)}$ Therefore, the inductions of IL-18, IFN- $\gamma$ and iNOS in the small intestinal mucosa of IMC-administered AA rats may occur in infiltrating macrophages.

Further studies are needed to determine whether the intestinal ulcerogenic lesions of IMC-administered AA rats is able to suppress by the regulation of IL-18. Therefore, we are now planning to investigate the effect of IL-18 inhibitors and antibodies on the small intestinal mucosa of IMC-administered AA rats.

In conclusion, we found the enhancement of IL-18, IFN- $\gamma$ and NO levels in the jejunal and ileal mucosa of IMC-administered AA rats. It is possible that IL-18 expression in the jejunal and ileal mucosa of AA rats is more sensitive to IMC. In addition, the excessive IL-18 plays a role in the aggravation of intestinal ulcerogenic lesions in IMC-administered AA rats. These findings provide information that can be used to design further studies to develop potent NSAIDs that do not cause gastrointestinal toxicity.

Conflict of Interest The authors declare no conflict of interest.

\section{REFERENCES}

1) Hultqvist M, Olofsson P, Gelderman KA, Holmberg J, Holmdahl R. A new arthritis therapy with oxidative burst inducers. PLoS Med., 3, e348 (2006).

2) Escandell JM, Recio MC, Manez S, Giner RM, Cerda-Nicolas M, Rios JL. Cucurbitacin R reduces the inflammation and bone damage associated with adjuvant arthritis in lewis rats by suppression of tumor necrosis factor-alpha in T lymphocytes and macrophages. $J$. Pharmacol. Exp. Ther., 320, 581-590 (2007).

3) Kato S, Takeuchi K. Alteration of gastric ulcerogenic and healing responses in rats with adjuvant-induced arthritis. Jpn. J. Pharmacol., 89, 1-6 (2002).

4) Fries JF, Miller SR, Spitz PW, Williams CA, Hubert HB, Bloch DA. Toward an epidemiology of gastropathy associated with nonsteroidal antiinflammatory drug use. Gastroenterology, 96 (Suppl), 647-655 (1989).

5) Kato $\mathrm{S}$, Ito $\mathrm{Y}$, Nishio H, Aoi $\mathrm{Y}$, Amagase K, Takeuchi K. Increased susceptibility of small intestine to NSAID-provoked ulceration in rats with adjuvant-induced arthritis: involvement of enhanced expression of TLR4. Life Sci., 81, 1309-1316 (2007).

6) Vane JR. Inhibition of prostaglandin synthesis as a mechanism of action for aspirin-like drugs. Nat. New Biol., 231, 232-235 (1971).

7) Whittle BJ. Temporal relationship between cyclooxygenase inhibition, as measured by prostacyclin biosynthesis, and the gastrointestinal damage induced by indomethacin in the rat. Gastroenterology, 80, 94-98 (1981).
8) Weissenborn U, Maedge S, Buettner D, Sewing KF. Indomethacinincreased gastrointestinal lesions in relation to tissue concentration, food intake and bacterial invasion in the rat. Pharmacology, 30, 32-39 (1985).

9) Asako H, Kubes P, Wallace J, Gaginella T, Wolf RE, Granger DN. Indomethacin-induced leukocyte adhesion in mesenteric venules; role of lipoxygenase products. Am. J. Physiol., 262, G903-G908 (1992).

10) Yamada $T$, Deitch E, Specian RD, Perry MA, Sartor RB, Grisham MB. Mechanisms of acute and chronic intestinal inflammation induced by indomethacin. Inflammation, 17, 641-662 (1993).

11) Whittle BJ, Laszlo F, Evans SM, Moncada S. Induction of nitric oxide synthase and microvascular injury in the rat jejunum provoked by indomethacin. Br. J. Pharmacol., 116, 2286-2290 (1995).

12) Konaka A, Nishijima M, Tanaka A, Kunikata T, Kato S, Takeuchi K. Nitric oxide, superoxide radicals and mast cells in pathogenesis of indomethacin induced intestinal lesions in rats. Joutnsl of Pharmacology and Physiology, 50, 25-38 (1999).

13) Kato N, Mashita Y, Kato S, Mitsufuji S, Yoshikawa T, Takeuchi K. Sildenafil, an inhibitor of phosphodiesterase subtype 5, prevents indomethacin-induced small-intestinal ulceration in rats via a $\mathrm{NO} /$ cGMP-dependent mechanism. Dig. Dis. Sci., 54, 2346-2356 (2009).

14) Kato S, Ohkawa F, Ito Y, Amagase K, Takeuchi K. Role of endothelial nitric oxide synthase in aggravation of indomethacin-induced gastric damage in adjuvant arthritic rats. J. Physiol. Pharmacol., 60, 147-155 (2009).

15) Nagai N, Fukuhata T, Ito Y, Usui S, Hirano K. Involvement of interleukin 18 in indomethacin-induced lesions of the gastric mucosa in adjuvant-induced arthritis rat. Toxicology, 255, 124-130 (2009).

16) Billingham ME. Models of arthritis and the search for anti-arthritic drugs. Pharmacol. Ther., 21, 389-428 (1983).

17) Sakuma S, Nishigaki F, Magari K, Ogawa T, Miyata S, Ohkubo Y, Goto T. FK506 is superior to methotrexate in therapeutic effects on advanced stage of rat adjuvant-induced arthritis. Inflamm. Res., 50, 509-514 (2001)

18) Ghayur T, Banerjee S, Hugunin M, Butler D, Herzog L, Carter A, Quintal L, Sekut L, Talanian R, Paskind M, Wong W, Kamen R, Tracey D, Alien H. Caspase-1 processes IFN-gamma-inducing factor and regulates LPS-induced IFN-gamma production. Nature, $\mathbf{3 8 6}$, 619-623 (1997)

19) Gu Y, Kuida K, Tsutsui H, Ku G, Hsiao K, Fleming MA, Hayashi N, Higashino K, Okamura H, Nakanishi K, Kurimoto M, Tanimoto T, Flavell RA, Sato V, Harding MW, Livingston DJ, Su MS. Activation of interferon-gamma inducing factor mediated by interleukinlbeta converting enzyme. Science, 275, 206-209 (1997).

20) Torigoe K, Ushio S, Okura T, Kobayashi S, Taniai M, Kunikata T, Murakami T, Sanou O, Kojima H, Fujii M, Ohta T, Ikeda M, Ikegami H, Kurimoto M. Purification and characterization of the human interleukin-18 receptor. J. Biol. Chem., 272, 25737-25742 (1997).

21) Kim SH, Reznikov LL, Stuyt RJ, Selzman CH, Fantuzzi G, Hoshino T, Young HA, Dinarello CA. Functional reconstitution and regulation of IL-18 activity by the IL-18R beta chain. J. Immunol., 166, 148-154 (2001).

22) Nakanishi K, Yoshimoto T, Tsutsui H, Okamura H. Interleukin-18 regulates both Th1 and Th2 responses. Annu. Rev. Immunol., 19, 423-474 (2001).

23) Hoshino K, Tsutsui H, Kawai T, Takeda K, Nakanishi K, Takeda $Y$, Akira S. Cutting edge: generation of IL-18 receptor-deficient mice: evidence for IL-1 receptor-related protein as an essential IL-18 binding receptor. J. Immunol., 162, 5041-5044 (1999).

24) Chomczynski P, Sacchi N. Single-step method of RNA isolation by acid guanidinium thiocyanate-phenol-chloroform extraction. Anal. Biochem., 162, 156-159 (1987).

25) Bradford MM. A rapid and sensitive method for the quantitation of microgram quantities of protein utilizing the principle of proteindye binding. Anal. Biochem., 72, 248-254 (1976). 
26) Nagai N, Liu Y, Fukuhata T, Ito $Y$. Inhibitors of inducible nitric oxide synthase prevent damage to human lens epithelial cells induced by interferon-gamma and lipopolysaccharide. Biol. Pharm. Bull., 29, 2077-2081 (2006).

27) Aizawa $Y$, Akita K, Taniai M, Torigoe K, Mori T, Nishida Y, Ushio S, Nukada Y, Tanimoto T, Ikegami H, Ikeda M, Kurimoto M. Cloning and expression of interleukin-18 binding protein. FEBS Lett., 445, 338-342 (1999).

28) Novick D, Kim SH, Fantuzzi G, Reznikov LL, Dinarello CA, Rubinstein M. Interleukin-18 binding protein: a novel modulator of the Th1 cytokine response. Immunity, 10, 127-136 (1999).

29) Hurgin V, Novick D, Rubinstein M. The promoter of IL-18 binding protein: activation by an IFN-gamma-induced complex of IFN regulatory factor 1 and CCAAT/enhancer binding protein beta. Proc. Natl. Acad. Sci. U.S.A., 99, 16957-16962 (2002).

30) Boughton-Smith N, Evans SM, Laszlo F, Whittle BJ, Moncada S. The induction of nitric oxide synthase and intestinal vascular permeability by endotoxin in the rat. Br. J. Pharmacol., 110, 1189-1195 (1993).

31) Tanaka A, Kunikata T, Mizoguchi H, Kato S, Takeuchi K. Dual action of nitric oxide in pathogenesis of indomethacin-induced small intestinal ulceration in rats. J. Physiol. Pharmacol., 50, 405-417 (1999).

32) Lowenstein CJ, Alley EW, Raval P, Snowman AM, Snyder SH, Russell SW, Murphy WJ. Macrophage nitric oxide synthase gene: two upstream regions mediate induction by interferon gamma and lipopolysaccharide. Proc. Natl. Acad. Sci. U.S.A., 90, 9730-9734
(1993)

33) Xie QW, Whisnant R, Nathan C. Promoter of the mouse gene encoding calcium-independent nitric oxide synthase confers inducibility by interferon gamma and bacterial lipopolysaccharide. J. Exp. Med., 177, 1779-1784 (1993).

34) Heitmeier MR, Scarim AL, Corbett JA. Interferon-gamma increases the sensitivity of islets of Langerhans for inducible nitric-oxide synthase expression induced by interleukin 1. J. Biol. Chem., 272, 13697-13704 (1997).

35) Heitmeier MR, Scarim AL, Corbett JA. Prolonged STAT1 activation is associated with interferon-gamma priming for interleukin1-induced inducible nitric-oxide synthase expression by islets of Langerhans. J. Biol. Chem., 274, 29266-29273 (1999).

36) Chen CW, Chang YH, Tsi CJ, Lin WW. Inhibition of IFN-gammamediated inducible nitric oxide synthase induction by the peroxisome proliferator-activated receptor gamma agonist, 15-deoxy-delta 12,14-prostaglandin J2, involves inhibition of the upstream Janus kinase/STAT1 signaling pathway. J. Immunol., 171, 979-988 (2003).

37) Burbach GJ, Naik SM, Harten JB, Liu L, Dithmar S, Grossniklaus $\mathrm{H}$, Ward SL, Armstrong CA, Caughman SW, Ansel JC. Interleukin-18 expression and modulation in human corneal epithelial cells. Curr. Eye Res., 23, 64-68 (2001).

38) Sugawara S, Uehara A, Nochi T, Yamaguchi T, Ueda H, Sugiyama A, Hanzawa K, Kumagai K, Okamura H, Takada H. Neutrophil proteinase 3-mediated induction of bioactive IL-18 secretion by human oral epithelial cells. J. Immunol., 167, 6568-6575 (2001). 